\title{
Tine testing in HIV positive patients
}

\author{
Stephen P Higgins, Caroline S Bradbeer, Nigel T Bateman
}

\begin{abstract}
Background-The incidence of tuberculosis is increased in HIV positive patients. Purified protein derivative (PPD, tuberculin) testing has not been performed routinely on patients infected with HIV in the UK and its usefulness in diagnosing tuberculosis in these patients is unclear.

Methods-198 HIV positive patients were Tine tested and a CD4+ lymphocyte count and chest radiograph were performed. Of the 179 male patients 164 were homosexual or bisexual, 11 were injecting drug users (IDUs), and four were both homosexual and IDUs. Of 19 women 14 were heterosexual and five were IDUs. Patients assessed their own skin reactions at 72 hours, recording the grade on a card which was returned by post. Patients with a grade 0 reaction were requested to have a second test one month later.
\end{abstract}

Results-Details were available on 168 of the 198 patients. Grade 0 reactions occurred in 89 of the 168 patients, requiring a second Tine test, and 73 completed Tine 2 results were received. Of 57 patients with CD4+ lymphocyte counts below $200 / \mathrm{mm}^{3}$, low grade PPD reactivity was seen in 18 on Tine 1 and nine on Tine 2. No history of BCG immunisation of tuberculosis was found in 33 Tine positive patients. Two patients treated for tuberculosis in the previous six months were PPD positive with CD4t counts of $60 / \mathrm{mm}^{3}$ and $4 / \mathrm{mm}^{3}$ respectively.

Conclusions-PPD reactivity may be maintained despite a CD4+ count of $100 / \mathrm{mm}^{3}$ or less when there is a history of tuberculosis or BCG immunisation.

(Thorax 1993;48:831-834)

The incidence of tuberculosis is increased in HIV positive patients, ${ }^{1-3}$ but the degree of overlap between HIV infection and tuberculosis varies. In the USA overlap is greatest in urban immigrants ${ }^{4}$ and injecting drug users (IDUs), ${ }^{5}$ a situation largely mirrored in southern Europe. However, in England and Wales the incidence of tuberculosis is highest in immigrants from the Indian subcontinent, ${ }^{6}$ whereas HIV infection is commonest in homosexual men between the ages of 25 and 44. ${ }^{7}$ Although it has recently been recommended that all HIV positive individuals should routinely be tuberculin tested, ${ }^{7}$ there has been little enthusiasm for this policy in the UK as there has, to date, been no reported increase in the incidence of tuberculosis in this group, and the interpretation of purified protein derivative (PPD, tuberculin) skin tests is complicated by routine BCG immunisation and the development of anergy associated with deficient cellular immunity. It has been reported that PPD reactivity is reduced and anergy develops in HIV positive IDUs compared with HIV negative IDUs from the same clinic. ${ }^{8-12}$ In the report by Robert et $a l^{10}$ only one of $25 \mathrm{HIV}$ positive IDU patients on a methadone rehabilitation programme was PPD positive despite all having received BCG in childhood or infancy, and none had a CD4 + lymphocyte count of $<340 / \mathrm{mm}^{3}$. These results are surprising as Selwyn et $a l^{8}$ and Graham et al ${ }^{12}$ both report preservation of PPD reactivity in HIV positive individuals, especially when the CD4+ count is $>350 / \mathrm{mm}^{3}$. The usefulness of PPD testing in the diagnosis of tuberculosis and the detection of the presence of anergy remains uncertain. St Thomas' Hospital notifies between 90 and 100 cases of tuberculosis each year and the HIV unit has a substantial number of patients from sub-Saharan Africa.

We decided to Tine test our HIV positive patients to determine the PPD reaction and relate this to the $\mathrm{CD} 4+$ lymphocyte count. By repeating the test annually or when the CD4 + lymphocyte count dropped below each centile level (whichever was sooner) we can determine whether PPD reactivity is lost with declining $\mathrm{CD} 4+$ counts and whether reactivity is enhanced if tuberculosis is acquired (or even reactivated). We intend to use this information to assess the usefulness of PPD reactivity in the diagnosis of tuberculosis at different CD4 + levels and in deciding who should receive short term or long term chemoprophylaxis. The results of the first 198 patients tested are presented.

The setting of the study is a dedicated HIV clinic located in the department of genitourinary medicine. Separate clinics are held for some HIV positive IDUs and all haemophiliacs, and these are excluded from the study. However, the patients included in the study are a representative cross section of those seen in the clinic.

\section{Methods}

Since July 1991198 patients have been enrolled. Of a total of 179 male patients 164 
Table 1 Patients grouped by Tine test result and CD4+ lymphocyte count (Tine 1 is the initial and Tine 2 the repeat test in those negative on Tine 1)

\begin{tabular}{|c|c|c|c|}
\hline & $\begin{array}{l}\text { CD4+ count } \\
<100 / \mathrm{mm}^{3}\end{array}$ & $\begin{array}{l}\text { CD4+ count } \\
100-199 / \mathrm{mm}^{3}\end{array}$ & $\begin{array}{l}\text { CD4 }+ \text { count } \\
200+/ m^{3}\end{array}$ \\
\hline \multicolumn{4}{|c|}{ Patients $(n=149)$ from $W H O$ pattern 1 countries } \\
\hline \multicolumn{4}{|c|}{ Tine 1 grade: } \\
\hline 0 & $20(17)$ & $16(11)$ & $46(33)$ \\
\hline 1 & 9(4) & $5(4)$ & $42(35)$ \\
\hline 2 & $1(1)$ & $2(1)$ & $7(3)$ \\
\hline 3 & 0 & 0 & 0 \\
\hline 4 & 0 & 0 & $1(1)$ \\
\hline \multicolumn{4}{|c|}{ Tine 2 grade: } \\
\hline 0 & $11(9)$ & $8(6)$ & $19(12)$ \\
\hline 1 & $5(4)$ & $3(2)$ & $12(6)$ \\
\hline 2 & 0 & 1(1) & $3(3)$ \\
\hline 3 & 0 & 0 & 0 \\
\hline 4 & 0 & 0 & 0 \\
\hline \multicolumn{4}{|c|}{ Patients ( $n=19)$ from countries where tuberculosis is endemic } \\
\hline \multicolumn{4}{|c|}{ Tine 1 grade: } \\
\hline 0 & $2(2)$ & $1(0)$ & $4(2)$ \\
\hline 1 & 0 & 0 & $3(1)$ \\
\hline 2 & $1(1)$ & 0 & $4(2)$ \\
\hline 3 & 0 & 0 & $4(1)$ \\
\hline 4 & 0 & 0 & 0 \\
\hline \multicolumn{4}{|c|}{ Tine 2 grade: } \\
\hline 0 & $2(2)$ & $1(0)$ & $3(3)$ \\
\hline 1 & 0 & 0 & $1(0)$ \\
\hline 2 & 0 & 0 & 0 \\
\hline 3 & 0 & 0 & 0 \\
\hline 4 & 0 & 0 & 0 \\
\hline
\end{tabular}

Figures in parentheses indicate number of patients with a definite history of BCG immunisation.

were homosexual or bisexual, 11 were IDUs, and four were both homosexual and IDUs. Of 19 female patients 14 were heterosexual (10 from Uganda) and five were IDUs. All patients were asked about previous BCG immunisation (and examined for a scar), previous tuberculosis, and contact with others with tuberculosis. A Tine test was administered by one of four nurses trained in the technique. Particular attention was given to this training and the nurses' technique was rechecked during the course of the study. A CD4 + lymphocyte count was performed on the day of the Tine test. A chest radiograph (if not previously done in the HIV clinic) was taken. Patients were given a record card and instructed to mark the diagram on the card which most closely resembled their skin reaction 72 hours after the test. In view of the

Table 2 Patients BCG negative or with BCG status unknown

\begin{tabular}{lcll}
\hline Final Tine grade & Number of patients & Median $C D 4+/ \mathrm{mm}^{3}$ & Range $C D 4+/ \mathrm{mm}^{3}$ \\
\hline Individuals from & WHO pattern 1 countries & & \\
0 & 11 & 275 & $50-850$ \\
1 & 20 & 380 & $40-1180$ \\
2 & 5 & 520 & $160-950$ \\
3 & 0 & - & - \\
4 & 0 & & \\
\multicolumn{1}{l}{ Individuals from } & areas where tuberculosis is endemic & 150 \\
0 & 1 & 390 & $220-700$ \\
1 & 3 & 620 & $4-640$ \\
2 & 3 & 480 & $370-1000$ \\
3 & 3 & - & - \\
4 & 0 & &
\end{tabular}

reliance on patient validation of the Tine test, great emphasis was placed on instructing the patients in the correct method of reading the skin reaction, in particular the importance of noting induration as opposed to erythema. The completed card was then returned by post. Patients recording a grade zero reaction were requested to undergo a second Tine test one month later to ensure that no PPD reactivity could be recorded through enhancement or "boosting" the previous reactivity. ${ }^{13}$

Chest radiographs were reported by the department of radiology and classified as "normal," "active tuberculosis," "old tuber- $\mathbb{\Phi}$ culosis," and "other" when abnormalities not thought to be due to tuberculosis were observed. Demographic data were obtained from the case notes.

Skin reactions were graded as high (3-4), low (1-2), and nil (0).

\section{Results}

Of 198 patients Tine tested 181 completed cards legibly, but full information is available on only 168 patients. Eighty nine of the 168 patients had no reaction to their initial Tine test (Tine 1) and were asked to have a second Tine test (Tine 2); 73 completed Tine 2 cards were received.

PATIENTS FROM WHO PATTERN 1 COUNTRIES (EUROPE, NORTH AMERICA, AUSTRALASIA) Of 53 patients with $\mathrm{CD} 4+$ lymphocyte counts $<200 / \mathrm{mm}^{3}$ low grade PPD reactivity was seen in 17 Tine 1 tests. Of 28 patients with CD 4 + counts $<200 / \mathrm{mm}^{3}$ having a Tine 2 test, nine showed low grade PPD reactivity (table 1). Twenty five patients with low grade PPD reactivity had no history of tuberculosis or BCG (table 2).

Only one patient had high grade PPD reactivity and he had no history of tuberculosis (table 3). One patient who had been treated for active tuberculosis within the previous six $\delta$ months had low grade PPD reactivity despite a very low $\mathrm{CD} 4+$ lymphocyte count (table 4).

PATIENTS FROM AREAS WHERE TUBERCULOSIS IS ENDEMIC (MAINLY SUB-SAHARAN AFRICA, ALSO WEST INDIES, SOUTH AMERICA, MAURTTIUS)

Of four patients with $\mathrm{CD} 4+$ counts $<200 / \mathrm{mm}^{3}$ only one showed low grade PPD reactivity on Tine 1 and the remaining three $\mathbb{D}$ showed no PPD reaction on Tine 2 (table 1). Six patients with low grade PPD reactivity $\frac{0}{\circ}$ had no history of tuberculosis or BCG (table 2).

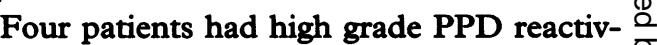
ity but no history of tuberculosis (table 3 ). Two patients who had been treated for active 8 tuberculosis within the previous six months had low grade PPD reactivity, two of these despite very low CD4 + lymphocyte counts (table 4). Two patients with disseminated Mycobacterium avium complex infection had no reaction to the Tine test with $\mathrm{CD} 4+$ counts of $50 / \mathrm{mm}^{3}$ and $70 / \mathrm{mm}^{3}$ respectively. 
Table 3 Patients with high grade (3 and 4) Tine reactions (all countries)

\begin{tabular}{|c|c|c|c|c|c|c|c|c|}
\hline Sex & $\begin{array}{l}\text { Country } \\
\text { of origin }\end{array}$ & $\begin{array}{l}\text { Tine } \\
\text { grade }\end{array}$ & $C D 4+/ \mathrm{mm}^{3}$ & $\begin{array}{l}\text { Chest } \\
\text { radiograph }\end{array}$ & $\begin{array}{l}\text { Old or } \\
\text { active } \\
\text { tuberculosis }\end{array}$ & $\begin{array}{l}B C G \\
\text { in past }\end{array}$ & $\begin{array}{l}C D C \\
\text { stage }^{*}\end{array}$ & $\begin{array}{l}\text { HIV risk } \\
\text { factor }\end{array}$ \\
\hline $\mathbf{M}$ & UK & 4 & 380 & Normal & No & Yes & II & Homosexual \\
\hline M & Mauritius & 3 & 370 & Normal & No & Yes & II & Homosexual \\
\hline F & Uganda & 3 & 480 & Othert & No & No & $\overline{I I}$ & $\begin{array}{l}\text { Heterosexual } \\
\text { intercourse } \\
\text { in } A \text { frica }\end{array}$ \\
\hline $\mathbf{M}$ & Uganda & 3 & 900 & Othert & No & No & II & $\begin{array}{l}\text { Heterosexual } \\
\text { intercourse } \\
\text { in Africa }\end{array}$ \\
\hline $\mathbf{M}$ & Trinidad & 3 & 1000 & Normal & No & No & II & Homosexual \\
\hline
\end{tabular}

*Centers for Disease Control staging of HIV disease (stage II = asymptomatic infection); tabnormalities seen not due to tuberculosis.

Table 4 Patients recently treated for tuberculosis

\begin{tabular}{|c|c|c|c|c|c|c|}
\hline Sex & $\begin{array}{l}\text { Country of } \\
\text { origin }\end{array}$ & Tine grade & $C D 4+/ \mathrm{mm}^{3}$ & $\begin{array}{l}\text { Site of } \\
\text { tuberculosis }\end{array}$ & $C D C$ stage ${ }^{*}$ & $\begin{array}{l}\text { HIV risk } \\
\text { factor }\end{array}$ \\
\hline M & Guyana & 2 & 4 & Lung & IV & $\begin{array}{l}\text { Heterosexual } \\
\text { intercourse in } \\
\text { Caribbean }\end{array}$ \\
\hline M & UK & 2 & 60 & Lung & IV & Homosexual \\
\hline $\mathbf{M}$ & Uganda & 2 & 260 & Pleura & IV & $\begin{array}{l}\text { Heterosexual } \\
\text { intercourse in } \\
\text { Africa }\end{array}$ \\
\hline
\end{tabular}

*Centers for Disease Control staging of HIV disease.

\section{Discussion}

The Tine test was chosen in preference to the Heaf or Mantoux tests because of its convenience (administered by a nurse and read by the patient), disposability (an important consideration in this population), and relative cheapness. At the time the study commenced disposable Heaf tests were not available but could be used equally well. The survey is incomplete in that not all patients attending the HIV clinic have entered the study and HIV positive patients attending other hospital departments, in particular the drug dependency unit, are not included. It is possible that this has contributed to the low rate of high grade PPD positivity. Most of the patients tested are homosexual men of UK origin and have a low risk of having had tuberculosis. However, patients attending HIV clinics may come into contact with individuals with open tuberculosis, putting them at risk. ${ }^{14}$ Patients whose PPD test convert from negative to positive should be investigated for tuberculosis in the usual way.

There is evidence that patients can read Heaf tests accurately. In a study in the Royal Victoria Dispensary, Edinburgh, patients attending for Heaf testing were very good at reading and recording the grade when compared with the grade assessed by the tuberculosis health visitor..$^{15}$ We know of no similar study using the Tine test but see no reason why it should be less easy for our patients, the majority of whom are highly motivated young men of UK origin, to assess accurately their own skin reactions. We have shown that positive PPD reactivity may be maintained with a
CD4 + lymphocyte count of $60 / \mathrm{mm}^{3}$ or less in patients recently treated for tuberculosis, and with a count of $100-200 / \mathrm{mm}^{3}$ when there is a history of BCG immunisation. Indeed, of 20 patients with $<100 / \mathrm{mm}^{3} \mathrm{CD} 4+$ lymphocytes who were initially non-reactive to the Tine test five showed positive reactivity on repeat Tine testing (table 1). None of these patients was unwell and none has developed clinical tuberculosis during follow up of up to 18 months. The immune memory for PPD can thus be boosted despite the CD4 + lymphocyte count being consistently below $100 / \mathrm{mm}^{3}$. This suggests the possibility of increased PPD reactivity remaining useful in the diagnosis of tuberculosis even when $\mathrm{CD} 4+$ counts are severely depressed. As in HIV negative patients, a negative test will not exclude the diagnosis of tuberculosis and clinical suspicion must lead to full investigation despite PPD negativity. ${ }^{6}$

Thirty one patients with low grade PPD reactivity and no history of BCG or tuberculosis, and five patients with high grade PPD reactivity and no evidence of old or active tuberculosis, were identified. It has been recommended that such patients be considered for antituberculous chemoprophylaxis. ${ }^{13}$ However, many of these patients may have a long life expectancy and long term prophylaxis with drugs such as isoniazid risks drug related toxicity and may promote emergence of drug resistant tuberculosis. Since it has not been shown that HIV positive patients who are in good health and have normal PPD reactivity should be treated differently from the HIV negative general population, our unit has adopted the standard indications for chemoprophylaxis outlined by the British Thoracic Society guidelines for control and prevention of tuberculosis. ${ }^{16}$ In 1990 a short report from Zambia suggested a protective effect for isoniazid $300 \mathrm{mg}$ daily with vitamin B alone. ${ }^{17}$ However, this setting is far removed from the HIV positive population in the UK and may not be applicable. We hope that our longitudinal study will allow us to comment upon whether our current policy requires modification.

Tine testing is relatively cheap and a useful way of assessing PPD reactivity in HIV positive patients. Information gained may be helpful in diagnosing tuberculosis in such individuals. When available, the Heaf gun with disposable heads will be preferable if current trials show it to be as reliable as the standard Heaf gun.

1 Centers for Disease Control. Tuberculosis United States, 1985 and the possible impact of the human lymphotropic virus type III/ymphadenopathy-associated virus infection. Morbidity and Mortality Weekly Report virus infection. Morbidity

2 Reider HL, Cauthen GM, Kelly GD, Bloch AB, Snider DE. Tuberculosis in the United States. $\mathcal{F} A M A$ 1989;262:385-9.

3 Slutkin G, Leowski J, Mann J. The effect of the AIDS epidemic on the tuberculosis problem and tuberculosis programmes and priorities for control and research. Bull programmes and priorities for control and

4 Pitchenik AE, Cole C, Russel BW, Fischl MA, Spira TJ, Snider TJ, et al. Tuberculosis, atypical mycobacteriosis, 
and the acquired immunodeficiency syndrome among Haitian and non-Haitian patients in South Florida. Ann Intern Med 1984;101:641-5.

5 Leads from the MMWR. Tuberculosis and acquired immunodeficiency syndrome-New York City. $¥ A M A$ 1988;259:338, 340, 345.

6 Medical Research Council Tuberculosis and Chest Diseases Unit. National survey of notifications of tuberculosis in England and Wales in 1983. BMF 1985;291:658-61.

7 Subcommittee of the Joint Tuberculosis Committee of the British Thoracic Society. Guidelines on the management of tuberculosis and HIV infection in the United Kingdom. BMF 1992;304:1231-3.

8 Selwyn PA, Hartel D, Lewis VA, Schoenbaum EE, Vermund SH, Klein RS, et al. A prospective study of the risk of tuberculosis among intravenous drug users with human immunodeficiency virus infection. $N$ Engl $f$ Med 1989;320:545-50.

9 Canessa PS, Fasano L, Lavecchia MA, Torraca A, Schiattone ML. Tuberculin skin test in asymptomatic HIV seropositive carriers. Chest 1989;96:1215-6.

10 Robert CF, Hirschel B, Rochat T, Deglon J. Tuberculin skin test reactivity in HIV seropositive intravenous drug addicts. $N$ Engl $\mathcal{F}$ Med 1989;321:1268.
11 Johnson MP, Coberly JS, Clermont HC, Chaisson RE, Davis HL, Losikoff $P$, et al. Tuberculin skin test reactivity among adults infected with human immunodeficiency virus. F Infect Dis 1992;166:194-8.

12 Graham NMH, Nelson KE, Solomon L, Bonds M, Rizzo RT, Scavotto J, et al. Prevalence of tuberculin positivity and skin test anergy in HIV 1-seropositive and seronegative intravenous drug users. $\mathscr{f} A M A$ 1992;267:369-73.

13 Caplin M. The tuberculosis test in clinical practice. London: Bailliere Tindall, 1980;47-8.

14 Edlin BR, Tokars JI, Grieco MH, Crawford JT, Williams J, Sordillo EM, et al. An outbreak of multidrug-resistant tuberculosis among hospitalised patients with the acquired immunodeficiency syndrome. $N$ Engl $f$ Med 1992;326:1514-21.

15 Selby CD, Allen MB, Leitch AG. How well do the general public read Heaf skin tests? Respir Med 1990;84:245-8.

16 Subcommittee of the Joint Tuberculosis Committee of the British Thoracic Society. Control and prevention of tuberculosis in Britain: an updated code of practice. BMF 1990;300:995-9.

17 Wadhawan D, Hira S, Mwansa N, Tembo G, Perine PL Isoniazid prophylaxis among patients with HIV-1 infection. Proceedings of the Sixth International Conference on
AIDS. San Francisco, June 1990, Abstract Th B 510. 